\title{
The Study of Variations of Extra-Hepatic Biliary Apparatus
}

\author{
T.Sobha devi ${ }^{1}$, P.Hari Krishna ${ }^{2}$ \\ ${ }^{1}$ Assistant professor, Department of Anatomy, S.V.Medical college, Tirupathi, India \\ ${ }^{2}$ Assistant professor, Department of E.N.T, S.V.Medical college, Tirupathi, india
}

\begin{abstract}
Secretions of the liver reach the duodenum by passing through the Extra-hepatic biliary apparatus. Any anatomical variations of this route can have serious implications due to disturbances in normal physiology. The present study was done on 50 embalmed cadavers during routine dissection practices for undergraduates in the dissection hall of Gandhi Medical College, Secunderabad. Observations were recorded in the following order. Position and anomalies of gallbladder, anomalies of cystic duct, anomalies of common hepatic duct, anomalies of common bile duct, anomalies of calots triangle. Five cases of accessory hepatic ducts and five cases of abnormal relation of cystic artery with common hepatic duct were found in this study. Awareness of the variations can also help the surgeons to carry out safe and complication free operative procedures. It is equally important for the radiologists to be aware of the possible variations while performing the diagnostic procedures Keywords: The Extra-hepatic biliary apparatus, Accessory hepatic duct, Cystic duct, Calots triangle. 3
\end{abstract}

\section{Introduction}

Extra-hepatic biliary apparatus consists of 1.Common hepatic duct 2.Gallbladder 3.Cystic duct 4.Common bile duct. The commencement is at the formation of common hepatic duct by the union of right and left hepatic ducts. It terminates by uniting with the pancreatic duct to form an ampulla, which opens on the major duodenal papilla. Review of the literature in this regard, showed several studies wherein variations of Extra-hepatic biliary apparatus were mentioned. It was observed that in the present times laparoscopic procedures have become common therapeutic methods. Since the laparoscopic surgeons have to work in a limited space, it is all the more important for them to be aware of the possible variations. Keeping this in view the present study was made as an attempt to look for variations of the Extra-hepatic biliary apparatus.

\section{Material And Methods}

The present study was done on 50 embalmed cadavers during routine dissection practices for undergraduates in the dissection hall of Gandhi Medical College, Secunderabad in 3 years period. The gallbladder, cystic duct common hepatic duct and upper part of common bile duct are supplied by cystic artery. It is a branch of right hepatic artery. It arises within the calots triangle. It divides into superficial and deep branches in the calots triangle, and supplies the gallbladder. Middle part of common bile duct is supplied by branches of hepatic artery, and lower part by the posterior superior pancreatico duodenal artery. Extra-hepatic biliary apparatus was drained by cystic veins, hepatic veins and posterior superior pancreatico duodenal vein.Calots triangle is a space bounded by common hepatic duct medially, and by the cystic duct inferiorly, and by the inferior surface of liver superiorly. The main content of this triangle is cystic arterys.Observations were recorded in the following order.Position and anomalies of gallbladder, anomalies of cystic duct, anomalies of common hepatic duct, anomalies of common bile duct, anomalies of calots triangle. Structure were coloured observations were noted and photographs were taken.

\section{Observations And Results}

TABLE 1,2, chart 1 , shows the summary of observations of present study. Fig 1 shows normal anatomy, fig 2-9 shows variations.

\section{Discussion}

The Gallbladder, is a part of Extra-hepatic biliary apparatus is commonly affected with cholelithiasis and cholecystitis. A thorough knowledge of the Extra-hepatic biliary apparatus could go a long way to minimize post operative complications.

In the present times laparoscopic cholecystectomy has become a very common procedure. keeping this in view a review of literature was done. Works of several anatomists, surgeons and radiologists where in anomalies pertaining to the apparatus and its blood supply were found. On taking up the present work , anomalies related to hepatic ducts and cystic arteries were found. Hence anomalies of the hepatic ducts and the 
cystic artery were viewed with extra interest. As early as 1803 a study by Luschka showed the presence of accessory hepatic ducts. However the exact number of cases found were not mentioned.

In 1996 Taourel p, et al Ref 17 had evaluated the anatomy of biliary tree with Magnetic resonance cholangiopancreatography in 171 patients and observed aberrant right hepatic ducts in 12 patients [9\%].In 2006 Uchiyama K, et al reported accessory hepatic ducts in $2.9 \%$ that is 30 cases out of 1041 cases he observed(TABLE 4,Chart 2).In the present study accessory hepatic ducts arose from right lobe of liver and joined different parts of Extra-hepatic biliary apparatus in 5 cases out of the 50 cadavers dissected, that is $10 \%$ of cases (Fig 3,4,5,6,7, Chart 2).

In the year 1996 Kullman E, et al Ref 8 in a prospective study in 513 cholangiograms, anatomical aberrations of bile ducts were found in 98 cases that is $8.4 \%$. The aberrant bile ducts opened into cystic duct.Lamah M, et al in 1999 found in a retrospective review of 2080 cases by preoperative cholangiography only 5 cases of accessory bile ducts.

In 2005 Delic J, Ref 3 worked on anatomical preparations and clinical radiographs and found aberrant bile ducts in $2.5 \%$ of cases. In the same year Izuishik, et al conducted multislice helical computed tomography. cholangiography studies in 113 patients and found aberrant bile ducts in 18 cases that is $16 \%$. In the present work no such anomaly was noticed.In 2001 Bernard P, Ref 1 et al described a rare biliary tract consisting of a double common bile duct. Only 23 cases of this type were reported on reviewing the literature.

In 1985Goiney RC, et al Ref 5 reported 3 cases of gallbladder duplication. Among them one was proven surgically, one was proven sonographically, and the other surgically proven intraperitoneal fibrous band, hence was not an actual gallbladder duplication band. William B sutter Ref 19 in 1991 reported a case of prenatal diagnosis of gallbladder duplication. In 1996J.-F. Gigot, et al Ref 7 reported a case of duplicated gallbladder by ultrasonography, oral cholecystography and intravenous cholangiography.In the present study no such anomaly has been noticed.

In 2004 Sophie Barnes MD, et al Ref 15 reported a case of triple gall bladder, each bearing a separate cystic duct, which joined to form a single cystic duct. The common cystic duct joined the common bile duct. The statistical data for the above mentioned variation was not provided. Lamah M, et al Ref 10 in 1999 reported cases of absent cystic duct in 3 out of 2080 cases. No such anomaly was noted in the present study.

Saidi H, et al Ref 14 in 2007 studied on the pattern of the arterial blood supply of 102 gallbladders. In $45.15 \%$ of cases the arteries approached the gallbladder anterior to common hepatic duct(TABLE 3, Chart 3).In the present study the above arterial pattern has been found in 5 cadavers out of the 50 , that is $10 \%$ of cases (Figure 2,6,8,9,Chart 3).

In 2002 Yamashita $\mathrm{K}$, et al Ref 20 reported a case with common bile duct dividing into 2 channels. Both channels opened separately into second part of duodenum. In his review he had come across 47 cases of double common bile duct. No such condition was observed during the present study.

\section{Summary\& Conclusion}

An attempt to study the variations of the Extra-hepatic biliary apparatus was made by dissecting 50 cadavers in Gandhi Medical College. Information about the work done on the Extra-hepatic biliary apparatus by other scientists was got by reviewing the available literature. It was observed that the findings were variable when compared with the earlier studies.

In the present study two types of variations were noted (Table 2,Chart 3). 1. Aberrant hepatic ducts were observed .Statistically the Incidence was found to be higher than in the previous studies. 2.Variations in the relation of cystic artery with the common hepatic duct were found. However, the incidence of this was observed to be low in comparision with the past study.

The present worker is of the opinion that the variations observed could definitely be useful to surgeons and radiologists. Further the worker proposes to continue the study, and make observations if any, useful to the medical fraternity

\section{References}

[1]. Bernard P, Le Borgne J, Dupas B, Kohnen-Shari N, Raoult S, Hamel A ; Double common bile duct with ectopic drainage into stomach. Surg RadiolAnat. 2001;23(4):269-72 PMID:12075184

[2]. Bernaschek W; Abberrant bile ducts as hazards in cholecystectomy.WienklinWochenschr.1954Feb19;66(7):11920.PMID:13157358

[3]. Delic J, Savkovic A, Isakovic E; Abberrant and accessory bile ducts. Med Art. 2005; 59(5):288-9 PMID :16134748

[4]. Foster JH, Wayson EE; Surgical significance of aberrant bile ducts. Am J Surg. 1962 Jul ; 104 :14-9.PMID:13894240

[5]. L Goiney RC, Schoenecker SA, Cyr DR, Shuman WP, Peters MJ, Cooperberg P; Sonography of gallbladder duplication and differential considerations. AJR Am J Roentgenol. 1985 Aug; 145(2):241-3.PMID:3895856

[6]. Izuishi K, Toyama Y, Nakano S, Goda F, Usuki H, Masaki T, Maeta H; Preoperative assessment of the aberrant bile duct using multislice computed tomography cholangiography. Am J Surg.2005 Jan; 189(1):53-5.PMID:15701492

[7]. J.-F. Gigot ,B. Van Beers, L. Goncette , J. Etienne , A. Collard ,P. Jadoul, A. Therasse , J.B. Otte and P .-J. Kestens; Laparoscopic treatment of gall bladder duplication. Surgical Endoscopy Journal 1997 May; 11:479-482.

[8]. Kullman E, Borch K, Lindstrom E, Svanvik J, Anderberg B; Value of routine intraoperative cholangiography in detecting aberrant bile ducts and bile duct injuries during laprascopic cholecystectomy. Br J Surg. 1996 Feb; 83(2):171-5.PMID:8689155 
[9]. Kwon AH, Yanagimoto H, Matsui Y, Imamura A; Agenesis of gallbladder with hypoplastic cystic duct diagnosed at laparoscopy. surg Laparosc Endosc Percutan Tech.2006 Aug;16(4):251-4.PMID:16921307

[10]. Lamah M, Dickson GH; Congenital anatomical abnormalities of the Extra-hepatic biliary duct. Surg Radiol Anat. 1999;21(5):3257.PMID:10635096

[11]. Paras R. Kothari, Tarun Kumar, Ashish Jiwane , Sanjay Paul, Rajneesh Kutumbale and Bharati Kulkarni; Congenital- gallbladderduplication cyst. Springerlink-journal Article August 2002.

[12]. Pottakkat B, Sikora SS;Aberrant right hepatic duct presenting as empyema of gallbladder. Australos Radiol.2007 Dec;51 Suppl:B303-5.PMID: 17991091

[13]. S. Shrivastava, A Bose, S.K.Wankhede; A STUDY OF VARIATIONS OF EXTRAHEPATIC BILIARY TRACT AND RELATED ARTERAL PEDICLE AND CLINICAL IMPLICATIONS.J.Anat.Soc.India 2002;51(1):97-142

[14]. Saidi H, Karanja TM, Ogengo JA;Variant anatomy of the cystic artery in adult Kenyans. Clin Anat. 2007 Nov;20(8):9435.PMID:17948297

[15]. Sophie Barnes, MD, Hagith Nagar, MD, Charles Levine MD, Moshe Santo, MD, Amirsold, MD, DiegoMercer, MD, Ada Kessler, MD; Tripple Gall bladder.J Ultrasound Med 2004;23:1399-1402.

[16]. Sziberth K; Spontaneous rupture of aberrant bile ducts in the treatment of choledocholithiasis. Chirurg. 1957 May;28(5):2289.PMID:13437366

[17]. Taourel P, Bret PM, Reihold C, Barkun AN, Atri M; Anatomic variants of biliary tree: Radiology. 1996 May;199(2):5217.PMID:8668805

[18]. Uchiyama K, Tani M, Kawai M, Ueno M, Hama T, Yamaue H; Preoperative evaluation of the Extra-hepatic bile duct structure for laparoscopic cholecystectomy. Surg Endosc. 2006 Jul;20(7):1119-23.PMID:16703426

[19]. William B . Sutter, MD*, Philippejeanty, MD, PhD; Gallbladder, duplication. TheFetus-net-Gallbladder 2007.http://www.thefetus.net/

[20]. Yamashita K, Oka Y, Ukrami A, Iwamoto S, Tsunoda T, Eto T; Double common bile duct. A case report and review of the Japanese literature. Surgery. 2002 June;131(6):676-81.PMID:126

Table 1-Summary of observations

\begin{tabular}{|c|c|c|}
\hline S1 No. & Case No. & Observations \\
\hline 1 & $1,2,3,4,5$ & Normal \\
\hline 2 & 6 & $\begin{array}{l}\text { Cystic artery arose from the right hepatic artery outside } \\
\text { the calots triangle.It runs anterior to the common hepatic } \\
\text { duct (Figure 2). }\end{array}$ \\
\hline 3 & 7,8 & Normal \\
\hline 4 & 9 & $\begin{array}{l}\text { Accessory hepatic duct from right lobe of liver } \\
\text { joined the body of gallbladder (Figure } 3 \text { ). }\end{array}$ \\
\hline 5 & $\begin{array}{l}10,11,12,13,14, \\
15\end{array}$ & Normal \\
\hline 6 & 16 & $\begin{array}{l}\text { Accessory hepatic duct arose from gallbladder fossa of } \\
\text { liver and joined the body of gallbladder (Figure } 4 \text { ). }\end{array}$ \\
\hline 7 & $17,18,19,20$ & Normal \\
\hline 8 & 21 & $\begin{array}{l}\text { Accessory hepatic duct from right lobe of liver } \\
\text { joined common hepatic duct (Figure 5). }\end{array}$ \\
\hline 9 & $\begin{array}{l}22,23,24,25,26 \\
27\end{array}$ & Normal \\
\hline 10 & 28 & $\begin{array}{l}\text { Cystic artery arose from the right hepatic artery } \\
\text { outside the calots triangle.It runs anterior to the common } \\
\text { hepatic duct (Figure 6). }\end{array}$ \\
\hline 11 & $29,30,31,32$, & Normal \\
\hline 12 & 33 & $\begin{array}{l}\text { Accessory hepatic duct from right lobe of liver } \\
\text { joined common hepatic duct(Figure } 7 \text { ). }\end{array}$ \\
\hline 13 & $34,35,36,37$ & Normal \\
\hline 14 & 38 & $\begin{array}{l}\text { Accessory hepatic duct from right lobe of liver joined } \\
\text { common hepatic duct. Cystic artery arose from the right } \\
\text { hepatic artery outside the calots triangle..It runs } \\
\text { anterior to the common hepatic duct (Figure } 8 \text { ). }\end{array}$ \\
\hline 15 & $39,40,41,42$ & Normal \\
\hline 16 & 43 & $\begin{array}{l}\text { Cystic artery arose from the right hepatic artery outside } \\
\text { the calots triangle.It runs anterior to the common hepatic } \\
\text { duct (Figure 9). }\end{array}$ \\
\hline 17 & 44 & $\begin{array}{l}\text { Cystic artery arose from the right hepatic artery outside } \\
\text { the calots triangle.It runs anterior to the common hepatic } \\
\text { duct. }\end{array}$ \\
\hline 18 & $\begin{array}{l}45,46,47,48,49 \\
50\end{array}$ & Normal \\
\hline
\end{tabular}


Table 2- Summary of observations of the present study

\begin{tabular}{|c|c|c|}
\hline Anomalies & Number & Percentage \\
\hline Accessory hepatic ducts & $5 / 50$ & $10 \%$ \\
\hline $\begin{array}{c}\text { Abnormal relation of cystic artery } \\
\text { with common hepatic duct }\end{array}$ & $5 / 50$ & $10 \%$ \\
\hline Normal cases & $40 / 50$ & $80 \%$ \\
\hline
\end{tabular}

Table 3-Comparison of abnormal relation of cystic artery with common hepatic duct

\begin{tabular}{|c|c|c|c|}
\hline S.No & Authors & Abnormality & Percentage \\
\hline 1 & Saidi H & $46.05 / 102$ & $45.15 \%$ \\
\hline 2 & Present study & $5 / 50$ & $10 \%$ \\
\hline
\end{tabular}

Table 4-Comparison of accessory hepatic ducts

\begin{tabular}{|c|c|c|c|}
\hline S.No & Authors & Accessory hepatic ducts & Percentage \\
\hline 1 & Taourel P & $12 / 171$ & $9 \%$ \\
\hline 2 & Uchiyama K & $30 / 1041$ & $2.9 \%$ \\
\hline 3 & Present study & $5 / 50$ & $10 \%$ \\
\hline
\end{tabular}

\section{Chart-1}
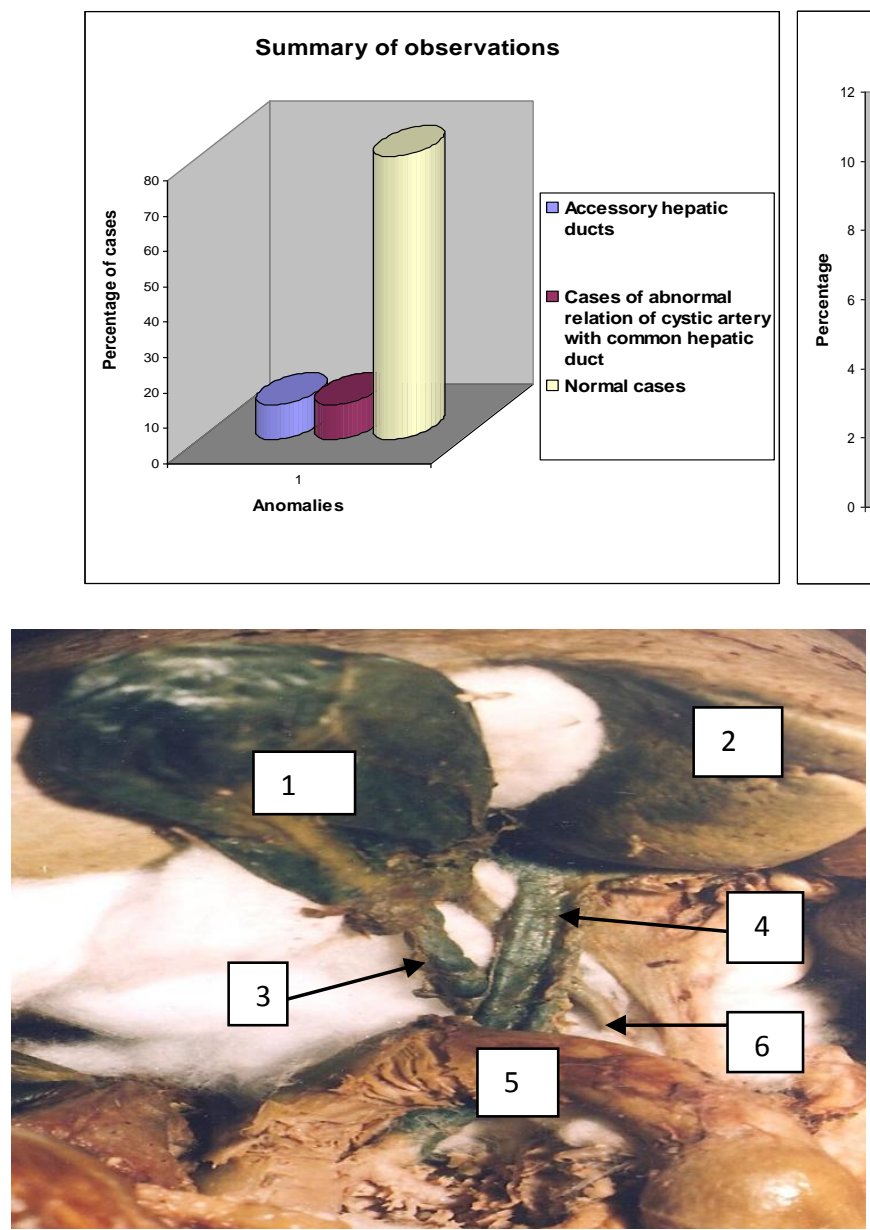

Figure 1-Normal anatomy of extra hepatic biliary apparatus. Indications: 1.Gallbladder,2.Liver,3.Cystic duct,4.Common hepatic duct,5.duodenum,6.cystic artery.

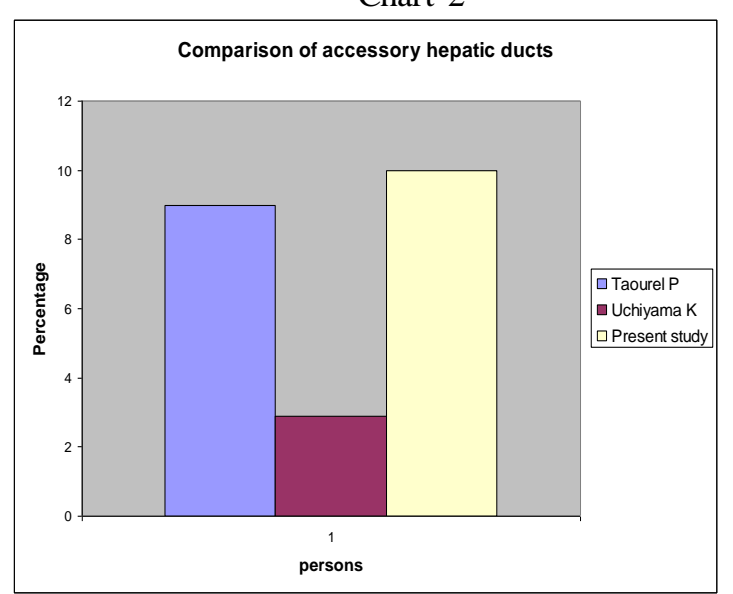

Chart-3

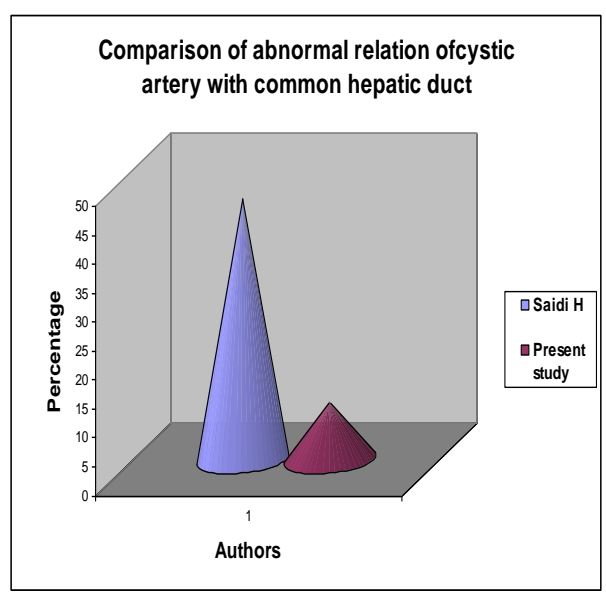




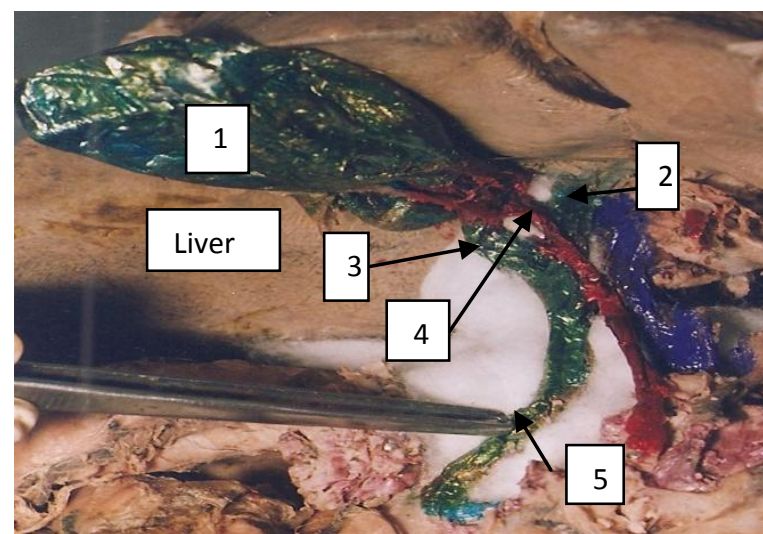

Figure 2-Cystic artery arose from the right hepatic artery outside the calots triangle.It runs anterior to the common hepatic duct. 1.Gallbladder,2.Common hepatic duct,3.Cystic duct,4.Cystic artery, 5.common bile duct.

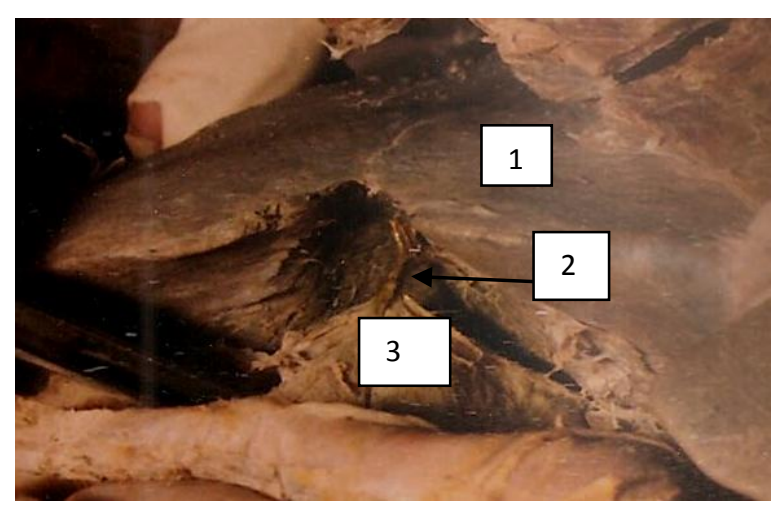

Figure 4-Accessory hepatic duct arose from gallbladder fossa of liver and joined the body of gallbladder.1.Liver,2.Accessory hepatic duct,3.Gallbladder.

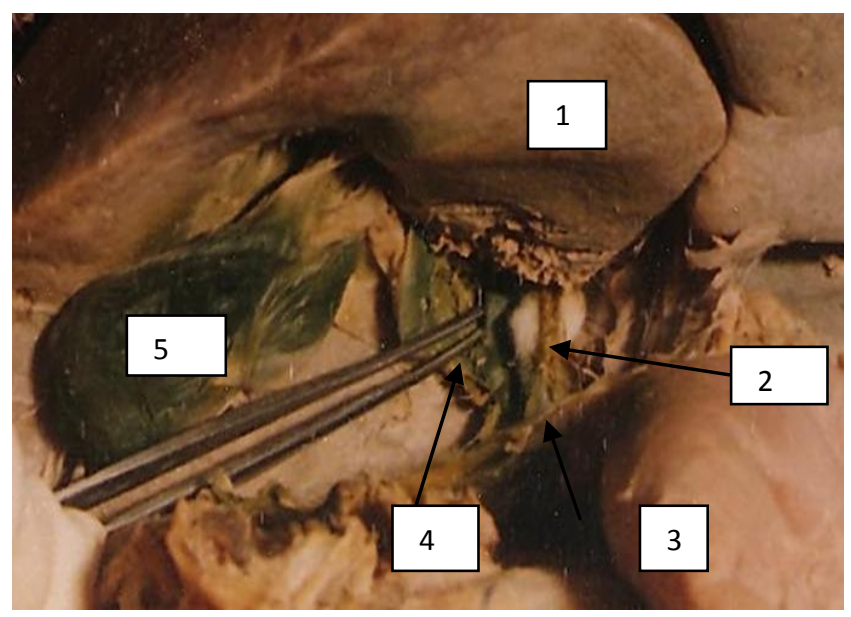

Figure 5-Accessory hepatic duct from right lobe of liver joined common hepatic duct.1.Liver,2.Accessory hepatic duct,3.common hepatic duct,4.Cystic duct,5.Gallbladder. 


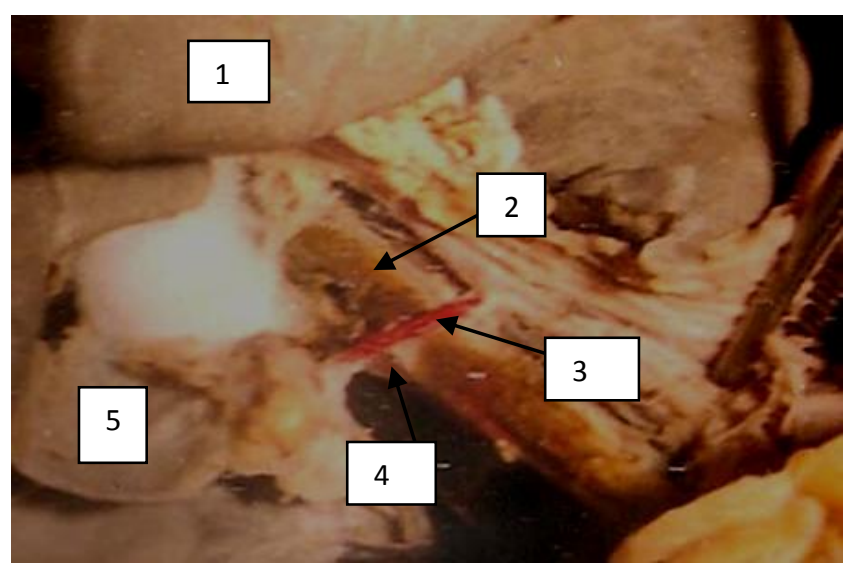

Figure 6-Cystic artery arose from the right hepatic artery outside the calots triangle.It runs anterior to the common hepatic duct.1.Liver,2.Common hepatic duct,3.Cystic artery, 4.Cystic duct,5.Gallbladder.

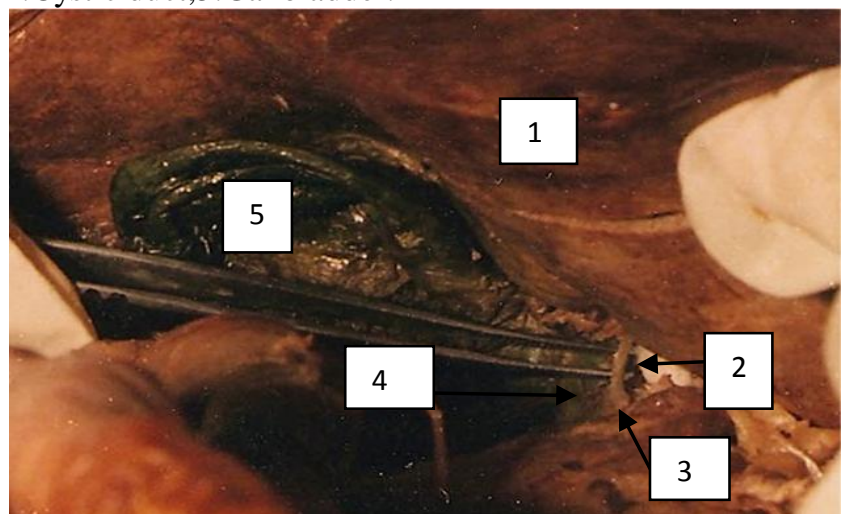

Figure 7-Accessory hepatic duct from right lobe of liver joined common hepatic duct.1.Right lobe of liver, 2.Accessory hepatic duct,3.Common hepatic duct, 4.Cystic duct,5.Gallbladder.

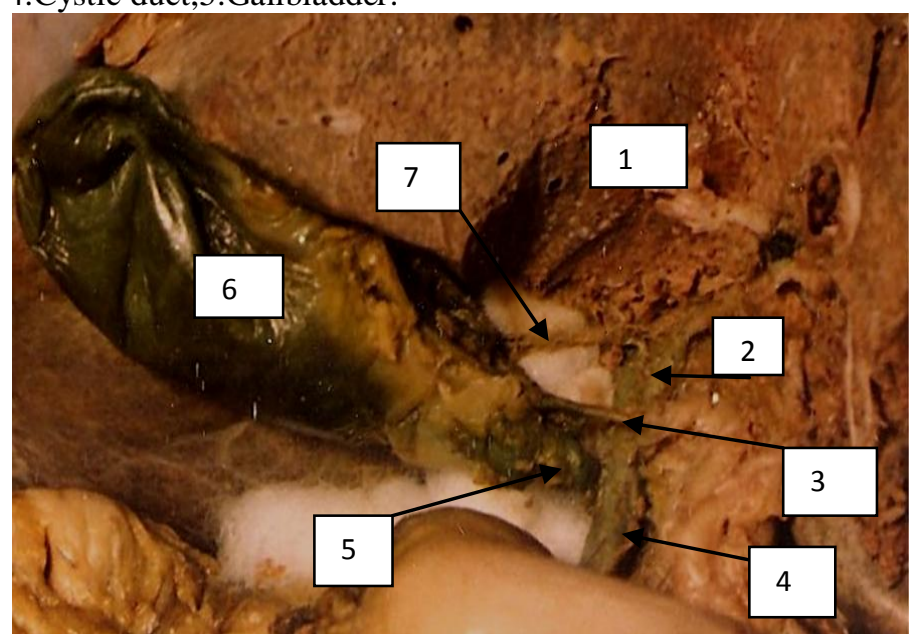

Figure 8-Accessory hepatic duct from right lobe of liver joined common hepatic duct.1.Right lobe of live. Cystic artery arose from the right hepatic artery outside the calots triangle.It runs anterior to the common hepatic duct.1. Right lobe of liver, 2.common hepatic duct,3.cystic artery,4.common bile duct, 5.cystic duct,6.Gallbladder,7.Accessory hepatic duct. 


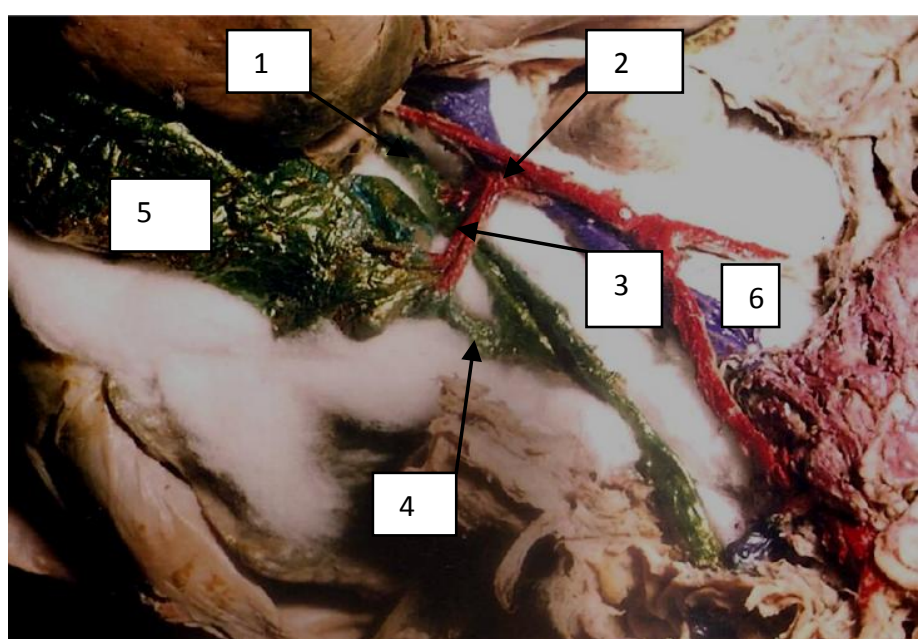

Figure 9-Cystic artery arose from the right hepatic artery outside the calots triangle.It runs anterior to the common hepatic duct.

1.Liver,2.Right hepatic artery,3.cystic artery,4.cystic duct,

5.Gallbladder,6.portal vein. 